\title{
Possible associations between callers' degree-of- worry and their socioeconomic status when contacting out-of-hours services: a prospective cohort study
}

Hejdi Gamst-Jensen

Kobenhavns Universitet

Sita LeBlanc Thilsted ( $\sim$ sita.thilsted@gmail.com )

Kobenhavns Universitet https://orcid.org/0000-0002-9337-2908

Fredrik Folke

Kobenhavns Universitet

Janne S. Tolstrup

Syddansk Universitet

Lau Caspar Thygesen

Syddansk Universitet

Original research

Keywords: Decision Support Systems, Emergency medicine, Telephone hotlines, Triage, Patient-centred Care, Decision Making, Help-seeking Behaviour, Socioeconomic Status, Marital Status, Ethnicity

Posted Date: June 5th, 2020

DOI: https://doi.org/10.21203/rs.3.rs-32941/v1

License: (c) (i) This work is licensed under a Creative Commons Attribution 4.0 International License.

Read Full License 


\section{Abstract \\ Background:}

Telephone triage within out-of-hours $(\mathrm{OOH})$ services aims to ascertain the urgency of a caller's medical condition in order to determine the correct type of health care needed, ensuring patient safety. To improve the triage process by increasing patient-centred communication, a triage tool has been developed, whereby callers are asked to rate their degree-of-worry (DOW) as a measure of self-evaluated urgency. Studies show that low socioeconomic status (SES), being single and non-Western ethnicity are associated to low self-rated health and morbidity and these factors may also be associated with high DOW. The aim of this paper was to examine if low SES, being single and non-Western ethnicity were associated to high DOW of callers contacting $\mathrm{OOH}$ services.

\section{Methods:}

A prospective cohort study design, at the $\mathrm{OOH}$ services for the Capital Region of Denmark. Over two weeks, 6,869 of 38,787 callers met the inclusion criteria: $\geq 18$ years, patients themselves or close relative/friend, reported DOW, had a valid personal identification number and gave informed consent. Callers were asked to report their DOW ( $1=$ minimal worry to $5=$ maximal worry), which was dichotomized into low (1-3) and high (4-5) DOW and linked to data from electronical medical records and Statistics Denmark. Socioeconomic factors (education and annual household income), marital status and ethnicity were assessed in relation to DOW by logistic regression.

\section{Results:}

High DOW was reported by $38.2 \%$ of the participants. Low SES (low educational level; OR $1.5,95 \% \mathrm{Cl}$ 1.3-1.7 and low annual household income; $1.5,1.3-1.6$ ) was associated with high DOW and so too was being single; 1.2, 1.1-1.3 and of non-Western ethnicity; 2.9, 2.5-3.4.

\section{Conclusions:}

Knowledge of the association of low SES, marital status as single and non-Western ethnicity with high DOW among callers to $\mathrm{OOH}$ services may give call handlers a better understanding of callers' DOW. If this does not correspond to the call handler's perception of urgency, this knowledge may further encourage patient-centred communication, aid the triage process and increase patient safety. A better understanding of socioeconomic variables and their relation to callers' DOW gives direction for future research to improve telephone triage of $\mathrm{OOH}$ services.

\section{Background}


Prehospital telephone triage within out-of-hours $(\mathrm{OOH})$ services is recognised as a means to reduce pressure and overcrowding of emergency departments and $\mathrm{OOH}$ clinics. Telephone triage aims to ascertain the urgency of a caller's medical condition in order to determine the correct type of health care needed, thus ensuring patient safety. However, due to the lack of non-verbal cues, urgency assessment is more challenging than in face-to-face consultations. Triage tools, e.g. computerised decision support systems are therefore used to aid the triage process. However, these tools focus mainly on medical information and less on affective information.

Patient-centered communication is defined as eliciting and understanding the patient's perspective of the illness including their wants, needs and preferences and acknowledging the patient's psychosocial and cultural circumstances, so a shared treatment goal can be reached. It is now identified as a central aspect for patient safety and is key to improving the quality of health care.' It has been suggested that patients expressing a potential need for hospitalisation should be thoroughly examined for possible severe illness and that patients' verbalisation of concerns and needs should be viewed as valid and encouraged by health care professionals.' This also pertains to the telephone triage process within $\mathrm{OOH}$ services. Therefore, a triage tool has been developed, whereby callers are asked to rate their degree-of-worry (DOW), on a five-point scale, as a measure of self-evaluated urgency. The goal is to increase patient-centred communication by encouraging patients' participation and thereby aiding call handlers in determining urgency and type of health care needed, potentially increasing patient safety. DOW has previously been shown to be feasible and associated with callers' illness representation. Furthermore, it has been shown that high DOW is strongly associated with hospitalisation. There are, however, many unexamined aspects regarding the implementation of DOW as a patient-reported outcome measure.

There is ample evidence that socioeconomic circumstances, e.g. education, household income and marital status influence individuals' health outcomes' and that individuals with low socioeconomic status (SES) are more likely to have low self-reported health and high morbidity and mortality. Furthermore, it has been demonstrated that individuals with low SES more often consult emergency departments and $\mathrm{OOH}$ services, even when their health status is taken into account.' This is assumed partly due to low health literacy, leading to difficulties in navigating the health care system, whereby individuals contact $\mathrm{OOH}$ services as an alternative to their general practitioner (GP). Evidence also suggest that marital status affects individuals health, where married individuals typically lead longer and healthier lives than singles. Finally, ethnicity is an important factor for health status and health-care utilization, where nonWestern Danes report a lower self-rated health and have higher rates of morbidity compared to ethnic Danes.

Knowing that individuals with low SES, single marital status and non-Western ethnicity are generally more ill, one could hypothesise that when calling $\mathrm{OOH}$ services these individuals would report a higher DOW. The association of callers' SES status, marital status and ethnicity with their DOW is, however, unknown. A greater insight in these possible associations may give call handlers a better understanding of callers' DOW reported during telephone triage. An increased knowledge and understanding of this 
triage tool may further encourage patient-centred communication, aid the assessment of urgency of a caller's medical condition and increase patient safety.

\section{Method}

\section{Aim}

The aim of this paper is to examine if low SES, marital status and non-Western ethnicity are associated to high DOW of callers contacting $\mathrm{OOH}$ services.

\section{Study design}

Data collected as a prospective cohort study with an embedded randomized controlled trial was linked with data on individual SES from Statistics Denmark. In the randomized controlled trial, it was examined whether call handlers' awareness of callers' DOW had an effect on triage response. Results showed that there was no difference between the intervention and control group.

\section{Setting}

The Copenhagen Emergency Medical Services, the Capital Region of Denmark and the $\mathrm{OOH}$ services are integrated into one organisation and can be reached through two telephone numbers; 112 , the Copenhagen Emergency Medical Services for life-threatening emergencies and 1813, the $\mathrm{OOH}$ services for acute, non-emergent medical calls. The $\mathrm{OOH}$ services are available from $4 \mathrm{pm}$ to $8 \mathrm{am}$ on weekdays and around the clock on weekends and holidays. Individuals may also call the $\mathrm{OOH}$ services for a referral to an emergency department, if they cannot get in touch with their GP during regular working hours. All access to acute care is pre-assessed by telephone triage. Annually, approximately one million calls are handled by call handlers (nurses/physicians) who triage the caller to self-care, GP, home visit, face-to-face assessment/consultation at a hospital, or direct hospitalisation.' Call handlers use a criterion-based electronic triage tool, which is locally developed and not validated.

\section{Data collection}

Callers to the $\mathrm{OOH}$ services from January 24th to February 9th, 2017, were invited to participate in the study. Inclusion criteria were age $\geq 18$ years and being able to link callers' unique PIN (personal identification) number to Statistics Denmark. Exclusion criteria were lack of consent, not being the patient themselves or a close relative/friend to the patient, repeat callers, not having a permanent PIN and not rating DOW (see Fig. 1). Via telephone survey, participants electronically reported their DOW on a fivepoint scale ( $1=$ minimal worry to $5=$ maximum worry) before being put through to a call handler. Callers' DOW was stored in their electronic medical record. An in-depth description of this data collection has been published previously. ${ }^{13}$

\section{Data sources}

Data was derived from two different sources: 
1. At the $\mathrm{OOH}$ services, callers' medical information, including PIN, gender and age are registered in their electronic medical record. Data on DOW was also stored in callers' electronic medical record.

2. Statistics Denmark is the central data resource for individual level data on e.g. highest attained education, annual household income, marital status and country of origin, which is linkable to each resident's unique PIN.

\section{Variables}

The socioeconomic variables were categorized as follows:

1) educational level; low: early childhood, primary and lower secondary education; International Standard Classification of Education (ISCED) $=0-2$, middle: upper and post-secondary education; ISCED = 3-4 and high: tertiary education, bachelor's, master's and doctoral level; ISCED = 5-8.

2) annual household income; low: Danish Kroner (DKK) < 189,460, middle: DKK 189,460 - 294,180 and high: DKK > 294,180,

3) marital status; single or married/cohabiting

4) ethnicity; Danish, non-Danish Western and non-Western

Age was categorized by $18-30,31-40,41-50,51-60,61-70,71-80$ and $>80$ years.

\section{Outcome measure}

DOW was dichotomized into two groups: low (DOW = 1-3) and high (DOW = 4-5), based on the association between DOW and hospitalization, where DOW $=4-5$ showed significantly higher odds for hospitalization than DOW $=1-3 .{ }^{13}$

\section{Analysis}

Associations between education, annual household income, marital status and ethnicity and high DOW were analysed separately, using logistic regression models adjusted for gender and continuous age. Results were reported as odds ratios (OR) and 95\% confidence intervals $(95 \% \mathrm{Cl})$.

\section{Results}

\section{Participants}

A total of 38,787 callers were invited to participate in the study. Of these, 25,885 callers declined participation, 699 were not patients themselves or a close relative/friend of the patient, 771 were repeated callers, 73 had a temporary PIN and 19 did not rate their DOW. This resulted in inclusion of 11,340 callers, where only adult callers ( $\geq 18$ years) ( $n=4,377$ excluded) that could be linked by their unique PIN to 
registers at Statistics Denmark ( $\mathrm{n}=94$ excluded), were included in the present study, resulting in analysis of a total of 6,869 callers (see Fig. 1 ).

DOW was rated as high by $38.2 \%$ of the 6,869 callers. The study population consisted mainly of females (58.3\%), with the proportions of females being similar in both the low (57.9\%) and high (59.0\%) DOW category. The mean age of those reporting a high DOW was 51.6 (standard deviation (SD) 20.9) years compared to 43.4 (SD 18.7) years for low DOW. The proportion of callers reporting high DOW increased with age; with $29.5 \%$ of callers aged $18-30$ years reporting high DOW compared to $57.5 \%$ of callers aged $>80$ years.

Educational level was registered for 6,573 callers, with most callers $(2,820 ; 41.1 \%)$ having a middle educational level. Information on household income was available for 6,129 callers, with the mean annual household income (DKK 266,986 (SD 209,711)) falling in the middle category. The majority of the callers $(3,847 ; 56 \%)$ was married or cohabiting. Finally, the majority $(83.1 \%)$ of callers were of Danish ethnicity, whereas only $4.2 \%$ were of non-Danish Western ethnicity and $12.7 \%$ were of non-Western ethnicity. 
Table 1

Descriptive information of study participants (n, \%)

\begin{tabular}{|c|c|c|c|}
\hline \multicolumn{4}{|c|}{ Demographics and socioeconomic variables on Degree-of-worry (DOW) } \\
\hline & Total & Low $(1-3)$ & High (4-5) \\
\hline & $n=6,869(\%)$ & $\mathrm{n}=4,243(61.8)$ & $\mathrm{n}=2,626(38.2)$ \\
\hline Gender & 4007 & $2,456(61.3)$ & $1,551(38.7)$ \\
\hline Female & 2862 & $1,787(62.4)$ & $1075(37.6)$ \\
\hline \multicolumn{4}{|l|}{ Male } \\
\hline Age (year) & $46.5 \pm 20.0$ & $43.4 \pm 18.7$ & $51.6 \pm 20.9$ \\
\hline \multicolumn{4}{|l|}{ Mean, SD } \\
\hline $18-30$ & 1,920 & $1,354(70.5)$ & $566(29.5)$ \\
\hline $31-40$ & 1,175 & $836(71.1)$ & $339(28.9)$ \\
\hline $41-50$ & 1,072 & $681(63.5)$ & $391(36.5)$ \\
\hline $51-60$ & 915 & $527(57,6)$ & $388(42.4)$ \\
\hline $61-70$ & 694 & $360(51,9)$ & $334(48.1)$ \\
\hline $71-80$ & 639 & $292(45.7)$ & $347(54.3)$ \\
\hline$>80$ & 454 & $193(42.5)$ & $261(57.5)$ \\
\hline Educational level & 1,763 & $968(54.9)$ & $795(45.1)$ \\
\hline \multicolumn{4}{|l|}{ Low } \\
\hline Middle & 2,820 & $1,773(62.9)$ & $1,047(37.1)$ \\
\hline High & 1,990 & $1,349(67.8)$ & $641(32.2)$ \\
\hline Missing & 296 & $153(51.7)$ & $143(48.3)$ \\
\hline Household income, DKK & 2211 & $1218(55.1)$ & $993(44.9)$ \\
\hline \multicolumn{4}{|l|}{ Low $(<189,460)$} \\
\hline Middle $(189,460$ - 291,175) & 1978 & $1225(61.9)$ & $753(38.1)$ \\
\hline High $(>291,175)$ & 1940 & $1300(67.0)$ & $640(33.0)$ \\
\hline Missing & 740 & $500(67.6)$ & $240(32.4)$ \\
\hline Marital status & 3,847 & $2,450(63.7)$ & 1,397 (36.3) \\
\hline \multicolumn{4}{|l|}{ Married/cohabiting } \\
\hline Single & 3,022 & $1,793(59.3)$ & $1,229(40.7)$ \\
\hline
\end{tabular}




\begin{tabular}{l|lcc|}
\hline \multicolumn{4}{|l|}{ Demographics and socioeconomic variables on Degree-of-worry (DOW) } \\
\hline $\begin{array}{lccc}\text { Ethnicity } \\
\text { Danish }\end{array}$ & 5,710 & $3,678(64.4)$ & $2,032(35.6)$ \\
\hline Non-Danish Western & 287 & $170(59.2)$ & $117(40.8)$ \\
\hline Non-Western & 872 & $395(45.3)$ & $477(54.7)$ \\
\hline
\end{tabular}
Ass
A

Low educational level was associated with high DOW (OR 1.5, 95\% $\mathrm{Cl} 1.3$ to 1.7), compared to middle educational level. Whereas, a high educational level was associated to reporting a low DOW compared to middle educational level. Low annual household income was associated with high DOW (OR 1.4, 95\% Cl 1.2 to 1.6), compared to middle annual household income. Whereas high annual household income was associated to a low DOW compared to middle annual household income. Being single was associated with high DOW (OR 1.3, 95\% Cl 1.1 to 1.5) compared to being married or cohabiting. Non-Western ethnicity was associated with high DOW (OR 2.9, 95\% Cl 2.5 to 3.4), compared to Danish ethnicity, but there was no significant association with non-Danish Western ethnicity (see Table 2). 
Table 2

Odds ratio $(\mathrm{OR}, 95 \% \mathrm{Cl})$ for reporting high degree-of-worry (DOW) by socioeconomic status adjusted for gender and age

\begin{tabular}{|c|c|}
\hline . & OR $(95 \% \mathrm{Cl})$ \\
\hline \multicolumn{2}{|l|}{ Educational level } \\
\hline Low & 1.5 (1.3 to 1.7$)$ \\
\hline Middle & 1.0 (Reference) \\
\hline High & 0.8 (0.7 to 0.9$)$ \\
\hline Missing & 1.7 (1.3 to 2.2 ) \\
\hline \multicolumn{2}{|l|}{ Household income (DKK) } \\
\hline Low & 1.4 (1.2 to 1.6$)$ \\
\hline Middle & 1.0 (Reference) \\
\hline Upper & 0.8 (0.7 to 0.9$)$ \\
\hline Missing & 1.1 (0.9 to 1.3$)$ \\
\hline \multicolumn{2}{|l|}{ Marital Status } \\
\hline Married/cohabiting & 1.0 (Reference) \\
\hline Single & 1.3 (1.1 to 1.5$)$ \\
\hline \multicolumn{2}{|l|}{ Ethnicity } \\
\hline Danish & 1.0 (Reference) \\
\hline Non-Danish Western & 1.3 (1.0 to 1.6$)$ \\
\hline Non-Western & 2.9 (2.5 to 3.4$)$ \\
\hline
\end{tabular}

\section{Discussion}

\section{Implications of the findings in context of existing research}

Previous studies have demonstrated an association between socioeconomic variables (individuals' SES, marital status and ethnicity) with morbidity and self-rated health. Low SES (low education ${ }^{15}$, and low annual household income') are associated with high morbidity and low self-rated health. The same is true for marital status as single and in Denmark, individuals of non-Western origin also have higher rates of morbidity. ${ }^{24}$ There is no direct explanation as to why low SES, marital status as single and nonWestern ethnicity are associated with high DOW. However, it could be speculated, whether the association 
between these socioeconomic variables and high DOW is caused by the general social gradient in health care both in detection as well as treatment of illness.'

\section{Strengths and limitations of this study}

The main strength of this study is the use of data regarding SES, marital status and ethnicity obtained from registers, thereby minimizing information bias of self-report of socioeconomic variables.

Furthermore, participants' DOW was obtained when they were seeking help before being put through to a call handler, thereby limiting the influence of the triage result. Limitations include a possible risk of selection bias among callers who declined to participate, however, selection bias was assessed in a previous study ${ }^{25}$ and no differences between participants and non-participants regarding gender, age, reason for contacting $\mathrm{OOH}$ services and triage response were found. Non-participation may, however, be more pronounced among callers with low SES due to low health literacy, callers with non-Western ethnicity due to possible language difficulties and callers who were extremely distressed when contacting the $\mathrm{OOH}$ services. One may also argue that, as callers with low SES, marital status as single and nonWestern ethnicity have higher morbidity and lower health literacy rates ${ }^{18}$, naturally they would more often have an increased sense of medical urgency, an association that previously been shown, leading to a high DOW. This possible bias, however, remains to be explored. The data includes missing variables of education and household income. The data on highest attained educational level is a little below the general coverage of the register (95.7\% vs $96.4 \%)$ and within the category of missing information an association with high DOW is observed.

\section{Conclusion}

\section{Summary of main findings}

There is a social and ethnic gradient in self-reported DOW when contacting an $\mathrm{OOH}$, with low SES, marital status as single and non-Western ethnicity being associated with high DOW.

\section{Relevance of this study: possible implications for health care providers and policy makers}

Previous studies have shown that the use of $\mathrm{OOH}$ services is significantly higher in areas with low SES and it is therefore important to understand callers' motivation for help-seeking in this context. As call handlers in $\mathrm{OOH}$ services cannot rely on visual cues in order to assess urgency during telephone triage, they must solely rely on verbal information given by callers, which may obscure their assessment of urgency. Moreover, as callers are unknown to the call handlers, their full medical history, SES and level of health literacy is not necessarily known. Experts within the field of emergency medicine decision-making recognise, that call handlers' perceptions may be influenced by mental shortcuts and an unconscious integration of preconceptions and stereotyping.' ' The clinical relevance of this study does not lie in the statistical significance but in the approach to the patient, and serves as a reminder that the symptoms the clinician deduce from a patient is the interpreted narrative. Incorporating DOW as an additional 
permanent triage tool may aid the triage process by encouraging patient participation, increasing patientcentred communication and giving callers the opportunity to voice their concerns, which may especially be advantageous to callers with lower health literacy or challenged verbal ability. Callers' DOW could thereby, act as a mental forcing strategy, potentially debiasing the call handler's perception of the caller. According to the Common-Sense Model of Self-Regulation (CSM) by Leventhal, a widely recognized theoretical framework, patients' perceptions of their illness, is based on prior experience, personal beliefs, discussions with others and cultural understandings and a relation between a patient's illness representation and self-evaluation of urgency or DOW has previously been shown. ${ }^{12}$ If the callers' DOW, therefore, does not correspond to the call handler's sense of urgency, the call handler may ask more indepth questions, leading to a better understanding of the patient's illness perception, especially in relation to DOW, possibly influencing and correcting the call handlers sense of urgency. Acknowledging the patient's DOW as valuable triage information will enable elicitation, attention to, and understanding of the individual meaning and significance of patient's symptoms.

Thus, when call handlers are presented with a high DOW from a caller, especially if this does not correspond to the call handler's perception of urgency, an awareness of the significant association to various socioeconomic varibles and high DOW, should urge call handlers to a more thorough questioning of the caller for possible severe illness, as this population group may have a higher risk of serious illness. This increase in patient-centred communication may aid the call handler in determining the correct type of health care needed, thus ensuring patient safety. Furthermore, the association of callers' SES, marital status and ethnicity with DOW when contacting $\mathrm{OOH}$ services adds to the growing awareness of the socioeconomic inequality in health and healthcare and the continuing necessity of minimizing this gap. This is a new area of research and this study gives direction for future research to further strengthen the evidence.

\section{Abbreviations}

$\mathrm{OOH}$

out-of-hours

DOW

degree-of-worry

SES

socioeconomic status

GP

general practitioner

PIN

personal identification number

ISCED

International Standard Classification of Education

DKK 
Danish Krone

OR

odds ratios

$\mathrm{Cl}$

confidence intervals

SD

standard deviation

\section{Declarations}

\section{Ethics approval and consent to participate:}

All participants gave informed consent. The study was approved by the Danish National Board of Health, reference number 3-3013-1416/1/ and the Danish National Data. Protection Agency PVH-2015-004, ISuite number: 04330. The Danish National Ethics Committee was consulted, and approval was not deemed necessary $\mathrm{H}-15016323$.

Consent for publication:

Not applicable

\section{Availability of data and materials:}

The datasets used and/or analysed during the current study are available from the corresponding authors on reasonable request.

Competing interests:

The authors declare that they have no competing interests.

\section{Funding:}

HGJ received grants from the Danish Foundation TrygFonden, The Danish Nurses' Association and the Laerdal Foundation. The funding sources had no influence in the study design, data collection, analysis or interpretation of data.

\section{Author's contributions:}

HGJ planned and conducted data collection and the extraction of data. FF supervised the data collection, data extraction and the process of the study. HGJ and SLT analysed the data. SLT drafted the 
manuscript. HGJ, JST and LCT supervised and contributed substantially to revisions. All authors read and approved the final manuscript.

\section{Acknowledgements:}

Not applicable

\section{References}

1. Würgler MW, Navne LE. Når sygeplejersker visiterer i lægevagten. Copenhagen: Dansk Sundhedsinstitut; 2010.

2. Leprohon J, Patel VL. Decision-making Strategies for Telephone Triage in Emergency Medical Services. Med Decis Making. 1995;15:240-53. doi:10.1177/0272989x9501500307.

3. Gravsersen DS. Out-of-hours telephone triage by nurses and doctors in Danish acute care settings A study of quality focusing on communication, safety and efficiency. Aarhus: Research Unit for General Practice, University of Aarhus; 2016.

4. Holmström I. Decision aid software programs in telenursing: not used as intended? Experiences of Swedish telenurses. Nurs \& Health Sci. 2007;9:23-8. doi:10.1111/j.1442-2018.2007.00299.x.

5. King A, Hoppe RB. "Best Practice" for Patient-Centered Communication: A Narrative Review. J Grad Med Educ. 2013;5:385-93. doi:10.4300/jgme-d-13-00072.1.

6. World Health Organization [Internet]. Patient safety - patients for patient safety: our programme c2019 [cited 2019 May 20]. Available from: http://www.who.int/patientsafety/patients_for_patient/programme/en/\#

7. Naughton CA. Patient-Centered Communication. Pharmacy. 2018;6:18. doi:10.3390/pharmacy6010018

8. Miyamichi R, Mayumi T, Asaoka M, et al. Evaluating patient self-assessment of health as a predictor of hospital admission in emergency practice: a diagnostic validity study. Emerg Med J. 2011;29:5705. doi:10.1136/emj.2010.105247.

9. Preston C, Cheater F, Baker R, et al. Left in limbo: patients' views on care across the primary/secondary interface. In: Clarke A, Allen P, Anderson S, et al., editors. Studying the Organisation and Delivery of Health Services. London and New York: Routledge and Taylor \& Francis Group; 2004. p. 55-63.

10. Ricci-Cabello I, Saletti-Cuesta L, Slight SP, et al. Identifying patient-centred recommendations for improving patient safety in General Practices in England: a qualitative content analysis of free-text responses using the Patient Reported Experiences and Outcomes of Safety in Primary Care (PREOSPC) questionnaire. Health Expect. 2017;20:961-72. doi:10.1111/hex.12537.

11. Gamst-Jensen H, Huibers L, Pedersen K, et al. Self-rated worry in acute care telephone triage: a mixed-methods study. Br J Gen Pract. 2018;68:e197-e203. doi:10.3399/bjgp18x695021. 
12. Thilsted SL, Egerod I, Lippert FK, et al. Relation between illness representation and selfreported degree-of-worry in patients calling out-of-hours services: a mixed-methods study in Copenhagen, Denmark. BMJ Open. 2018;8:e020401. doi: 10.1136/bmjopen-2017-020401.

13. Gamst-Jensen H. Patients' self-assessment of illness and injury in telephone triage using a novel degree-of-worry scale. Copenhagen: The Capital Region of Denmark; 2018.

14. World Health Organization [Internet]. 10 facts on health inequities and their causes c2019 [cited 2019 Apr 24]. Available from: https://www.who.int/features/factfiles/health_inequities/en/

15. Mackenbach JP, Stirbu I, Roskam AJ, et al. Socioeconomic Inequalities in Health in 22 European Countries. N Engl J Med. 2008;358:2468-81. doi: 10.1056/NEJMsa0707519.

16. Foraker RE, Rose KM, Chang PP, et al. Socioeconomic status and the trajectory of self-rated health. Age Ageing. 2011;40:706-11. doi:10.1093/ageing/afr069.

17. Jensen NL, Pedersen HS, Vestergaard M, et al. The impact of socioeconomic status and multimorbidity on mortality: a population-based cohort study. Clin Epidemiol. 2017;9:279-89. doi:10.2147/clep.s129415.

18. Jansen $\mathrm{T}$, Rademakers $\mathrm{J}$, Waverijn $\mathrm{G}$, et al. The role of health literacy in explaining the association between educational attainment and the use of out-of-hours primary care services in chronically ill people: a survey study. BMC Health Serv Res. 2018;18:394. doi:10.1186/s12913-018-3197-4.

19. Shona JK, Piercy H, Ibbotson R, et al. Who attends out-of-hours general practice appointments? Analysis of a patient cohort accessing new out-of-hours units. BMJ Open. 2018;8. doi:10.1136/bmjopen-2017-020308.

20. Kickbusch I, Pelikan JM, Apfel F, Tsouros AD: Health literacy: the solid facts. Copenhagen: The World Health Organization, regional office for Europe 2013.

21. Drummond N, McConnachie A, O'Donnell CA, et al. Social variation in reasons for contacting general practice out-of-hours: implications for daytime service provision? Br J Gen Pract. 2000;50:460-4.

22. Choi H, Marks NF. Socioeconomic status, marital status continuity and change, marital conflict, and mortality. J Aging Health. 2011;23(4):714-742. doi:10.1177/0898264310393339

23. Darlington $F$, Norman $P$, Ballas $D$, et al. Exploring ethnic inequalities in health: evidence from the Health Survey for England, 1998-2011. Diversity \& Equality in Health and Care. 2015;12. doi:10.21767/2049-5471.100032.

24. Vinther-Jensen K. Etniske Minoriteter i det danske sundhedsvæsen - en antologi. Copenhagen: Danish Health Authority; 2010. [cited 2019 Apr 9]. Available from: https://www.sst.dk/ /media/9FFE65223C8A47328A51CD7DBAFA7466.ashx

25. Gamst-Jensen, H., Frishknecht Christensen, E., Lippert, F. et al. Impact of caller's degree-of-worry on triage response in out-of-hours telephone consultations: a randomized controlled trial. Scand J Trauma Resusc Emerg Med. 2019;27:44. doi.org/10.1186/s13049-019-0618-2.

26. Årsrapportdata. Copenhagen: Emergency Medical Services Copenhagen, University of Copenhagen; 2015 and 2016. [cited 2017 Apr 15]. Available from: https://www.regionh.dk/om-region- 
hovedstaden/akutberedskabet/akutberedskabets-

aktivitetsdata/Documents/Aktivitet\%20for\%202015\%20og\%202016.pdf

27. Forde I, Nader C, Socha-Dietrich K, Oderkirk J, Colombo F. Primary Care Review of Denmark. OECD; 2016. [cited 2017 Apr 11]. Available from: https://www.oecd.org/health/health-systems/PrimaryCare-Review-of-Denmark-OECD-report-December-2016.pdf

28. Thygesen LC, Ersbøll AK. Danish population-based registers for public health and health-related welfare research: Introduction to the supplement. Scand J Public Health. 2011;39:8-10. doi:10.1177/1403494811409654.

29. Mainz J, Hess MH, Johnsen SP. The Danish unique personal identifier and the Danish Civil Registration System as a tool for research and quality improvement. Int J Qual in Health Care. 2019;31:717-20. doi:10.1093/intqhc/mzz008.

30. Moor I, Günther S, Knöchelmann A, et al. Educational inequalities in subjective health in Germany from 1994 to 2014: a trend analysis using the German Socio-Economic Panel study (GSOEP). BMJ Open. 2018;8:e019755. doi:10.1136/bmjopen-2017-019755.

31. Mortensen LH, Rehnberg J, Dahl E, et al. Shape of the association between income and mortality: a cohort study of Denmark, Finland, Norway and Sweden in 1995 and 2003. BMJ Open. 2016;6:e010974. doi:10.1136/bmjopen-2015-010974.

32. Hildebrand V, Kerm PV. Income Inequality and Self-Rated Health Status: Evidence from the European Community Household Panel. Demography. 2009;46:805-25. doi:10.1353/dem.0.0071.

33. Kondo N, Sembajwe G, Kawachi I, et al. Income inequality, mortality, and self rated health: metaanalysis of multilevel studies. Bmj. 2009;339. doi:10.1136/bmj.b4471.

34. Joutsenniemi KE, Martelin TP, Koskinen SV, et al. Official marital status, cohabiting, and self-rated health-time trends in Finland, 1978-2001. Eur J Public Health. 2006;16:476-83. doi:10.1093/eurpub/cki221.

35. Schwartz, K.L., Crossley-May, H., Vigneau, F.D. et al. Race, socioeconomic status and stage at diagnosis for five common malignancies. Cancer Causes Control. 2003;14:761-6. doi.org/10.1023/A:1026321923883.

36. Libungan B, Karlsson T, Hirlekar G, et al. Delay and inequality in treatment of the elderly with suspected acute coronary syndrome. International Journal of Cardiology. 2014;176:946-50. doi:10.1016/j.ijcard.2014.08.109.

37. Hyldgård VB, Johnsen SP, Støvring H, et al. Socioeconomic Status And Acute Stroke Care: Has The Inequality Gap Been Closed? Clinical Epidemiology. 2019;11:933-41. doi:10.2147/clep.s218322.

38. Medborgerskabsunders $\varnothing$ gelsen 2018. Copenhagen: The Ministry of Immigration and Integration; 2018. [cited 2019 May 28]. Available from: http://uim.dk/filer/nyheder2018/baggrundstabeller_medborgerskab_2018.pdf

39. Blom IM, Cohen ES, Eshuis LV, et al. Ethnic Differences in Health Literacy Among Young Adults in Amsterdam. HLRP: Health Literacy Research and Practice. 2018;2. doi:10.3928/2474830720180926-01. 
40. Campbell J. Patients perceptions of medical urgency: does deprivation matter? Family Practice. 1999;16:28-32. doi:10.1093/fampra/16.1.28.

41. Jansen T, Zwaanswijk M, Hek K, et al. To what extent does sociodemographic composition of the neighbourhood explain regional differences in demand of primary out-of-hours care: a multilevel study. BMC Family Practice. 2015;16. doi:10.1186/s12875-015-0275-0.

42. Croskerry P. Cognitive forcing strategies in clinical decisionmaking. Annals of Emergency Medicine. 2003;41:110-20. doi:10.1067/mem.2003.22.

43. Kahneman D, Klein G. Conditions for intuitive expertise: A failure to disagree. American Psychologist. 2009;64:515-26. doi:10.1037/a0016755.

44. Leprohon J, Patel VL. Decision-making Strategies for Telephone Triage in Emergency Medical Services. Medical Decision Making. 1995;15:240-53. doi:10.1177/0272989x9501500307.

45. Leventhal H, Meyer D, Nerenz D. The common sense representation of illness danger. In: Rachman $S$ (ed). Contributions to medical psychology. 1st edn,Vol 2.0xford: Pergamon Press, 1980:7-30.

46. Leventhal H, Phillips LA, Burns E. The Common-Sense Model of Self-Regulation (CSM): a dynamic framework for understanding illness self-management. Journal of Behavioral Medicine. 2016;39:935-46. doi:10.1007/s10865-016-9782-2.

47. Barsky AJ, Peekna HM, Borus JF. Somatic symptom reporting in women and men. J Gen Intern Med. 2001;16(4):266-275. doi:10.1046/j.1525-1497.2001.00229.x.

\section{Figures}




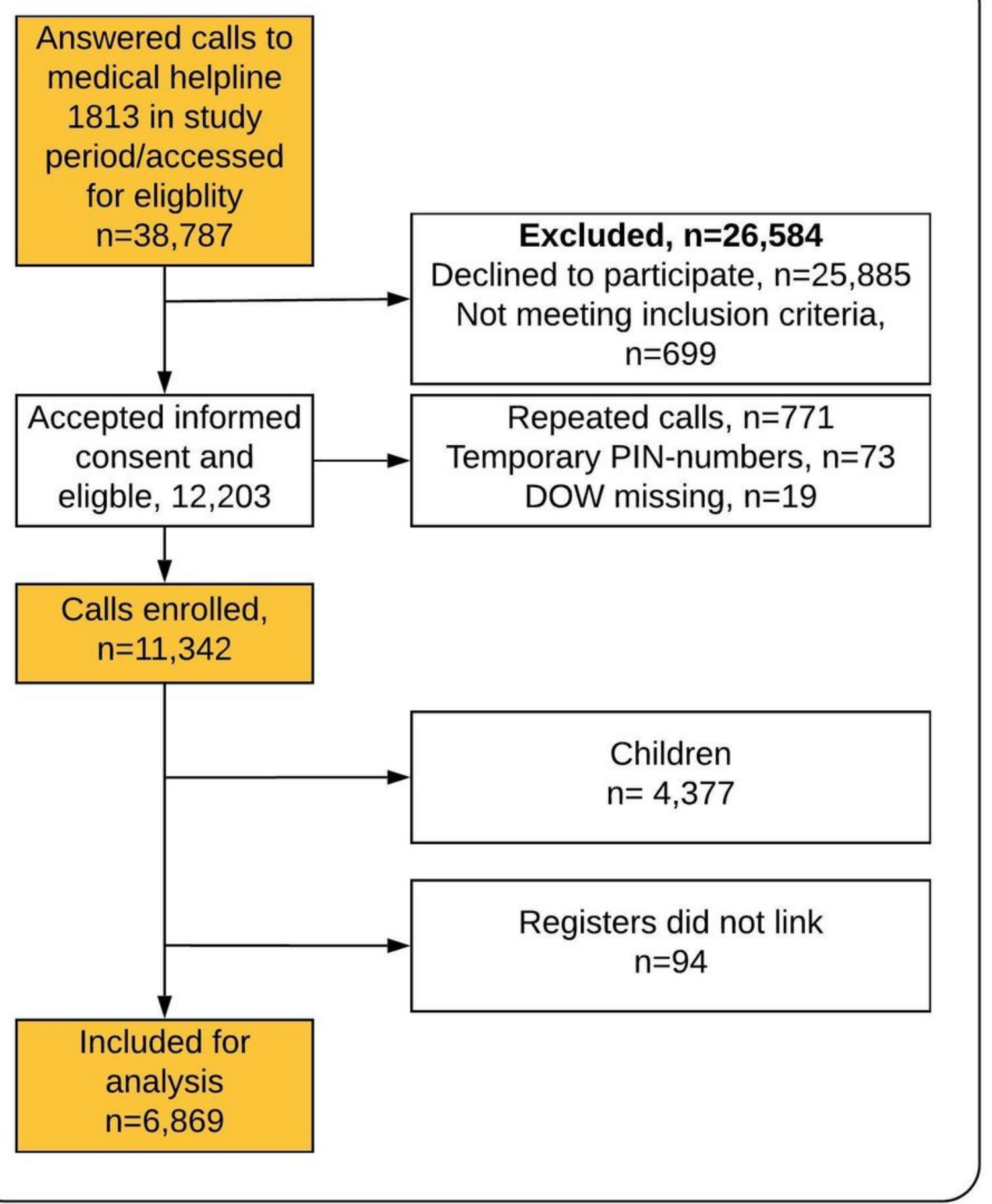

Figure 1

Flow diagram of participants' inclusion and exclusion criteria 